\title{
Factors associated with caesarean section at Bukavu Provincial Hospital in Democratic Republic of Congo
}

\author{
Mulongo Mbarambara Philémon ${ }^{1 *}$, Mwamini Chumbika Julie ${ }^{1}$, Mukanire Ntakwinja², \\ Kyambikwa Bisangamo Célestin ${ }^{1}$, Mvula Mwantito Théodore ${ }^{3}$
}

\begin{abstract}
${ }^{1}$ Department of Midwifery, Higher Institute of Medical Technology of Bukavu, DRC, Congo
${ }^{2}$ Department of Gynecology and Obstetrics, Panzi General Hospital, Bukavu, DRC, Congo

${ }^{3}$ Department of Obstetrics and Gynecology, Bukavu Provincial Hospital, DRC, Congo
\end{abstract}

Received: 10 October 2017

Accepted: 04 November 2017

\section{*Correspondence:}

Mulongo Mbarambara Philémon,

E-mail: philemon770@gmail.com

Copyright: (c) the author(s), publisher and licensee Medip Academy. This is an open-access article distributed under the terms of the Creative Commons Attribution Non-Commercial License, which permits unrestricted non-commercial use, distribution, and reproduction in any medium, provided the original work is properly cited.

\section{ABSTRACT}

Background: Caesarean section is the most common major surgery performed on women Worldwide. Even if caesarean can be useful for mother and foetus, it can provoke some medical and social complications like infection, expensive cost and maternal death. This study aimed at determining the factors associated with caesarean section in Bukavu, at the Provincial Hospital.

Methods: Data were collected retrospectively by exploring the files of childbirth established systematically for each pregnant woman. 466 files were exploited including 233 caesarean s (case) and 233 vaginal delivery (control). The normal childbirth which followed a caesarean was served as control. This study was a case-control. Logistic regression was used to model factor associated with caesarean section.

Results: During the study period, there were 2170 deliveries in which 491 of them by caesarean section $(22.6 \%)$. The factors associated with the caesarean section at the Provincial Hospital in Bukavu town were foetal distress, bleeding in the third trimester of the pregnancy, previous caesarean section, referral status and the moment of delivery (day shift).

Conclusion: This study recommends an adequate monitoring of the pregnancy and training of professionals in best practices; implementation and technical audit of caesarean with feedback can significantly reduce the rate of Caesarean section in this hospital. Also, allocation in equipment suitable for the treatment of pregnant women is necessary.

Keywords: Case control, Caesarean section, Factor associated, Provincial hospital

\section{INTRODUCTION}

In 2008, the World Health Organisation (WHO) estimated that over 350,000 women died in complications of childbirth. ${ }^{1}$ Ninety-nine per cent of these deaths occurred in resource-poor countries where access to family planning, antenatal care, and emergency obstetric services are limited. $^{2}$ It is worldwide known that caesarean can present several risks than a vaginal birth even if it is become nowadays one of obstetric intensive cares regarding its benefits for mother and baby. ${ }^{3}$

The WHO suggests that the level of caesarean section should range between $5 \%$ and $15 \%$ and no region in the world is justified with having a caesarean rate greater than $10 \%$ to $15 \%$ and not be less than $5 \% .^{4-6}$ Thus, both the upper and the lower limits have been discussed critically by several researchers. ${ }^{7-9}$ 
In many countries, particularly in the rich countries, the caesarean section rates increased progressively during the three last decades. ${ }^{10}$ Although, in many countries with limited resources, a weak access to a sure caesarean and convenient time is a substantial barrier to improve the results of the mothers and new-born babies' health. ${ }^{11}$

Possible causes for the increase include changes in sociodemographic factors and in clinical practices, as well as changes in the attitudes of health professionals and women towards caesarean section. ${ }^{12}$

Caesarean section is one of the components of emergency obstetric care to improve the maternal-fetal prognosis and when the complications occur during the pregnancy and the childbirth is one of interests of health system policies in the world. ${ }^{13}$

Although in DR Congo, the real caesarean section rate is not available because of the few studies done are fragmentary, the childbirth by caesarean takes an increasingly significant place. In a previous study conducted in a post-conflict environment of Bunia, southern of democratic republic of Congo, authors found that the caesarean section rate was $9.7 \% .^{14}$

The Democratic Republic of Congo (DRC) as a member of sub Saharan African country contributes to a large number in maternal and neonatal morbidity and mortality, did not achieve the millennium development goal regarding maternal and infantile health. Thus, the country must work hard in order to achieve the durable development goal especially in the research. Among the ways to improve the accessibility of compressive obstetric care in health institutions and contribute to the reduction of maternal and neonatal morbidity and mortality in the hospital, caesarean section which respects the standards of WHO should be performed.

Bukavu Provincial Hospital still the last referral level in south Kivu Province and there is no any research done on caesarean section at this hospital yet. In order to reduce the caesarean section rate, it is necessary to have a thorough understanding of the risk factors. So, the aim of the study was to identify factors associated with Caesarean section at Bukavu Provincial Hospital during the year 2014.

\section{METHODS}

\section{Population and study design}

A case-control study of women who had caesarean section (case) and those who had vaginal delivery (control) was conducted at the Bukavu Provincial Hospital during the same period going from $1^{\text {st }}$ January to $31^{\text {st }}$ December 2014. The sample size for study was of 466 subjects parted in 233 per category by using EPI Info 7.1.0 software at an estimated caesarean section prevalence rate of $9.7 \%$ with power set at $80 \%$ and confidence level at $95 \%$ with an Odds ratio (OR) of $\geq 2 .{ }^{14}$

The files of women who delivered single babies during the period of this study were exploited if only they were accessible and well filled. Although, the twin births, the childbirth out this hospital and the files lost or badly filled were excluded from this study.

Data were collected retrospectively by exploiting medical cards of childbirth booked during period going from $1^{\text {st }}$ January to $31^{\text {st }}$ December 2014. Permission was obtained from Bukavu Provincial Hospital prior to study conduction. Any information drawn from medical cards was kept confidential and only used for research purpose anonymously.

According to the design of the present study and study period considered (childbirth booked in 2014), we have just exploited medical cards of women. But, Ethical approval was obtained from "Commission Institutionnelle d'Ethique de l'Université Catholique de Bukavu" (Institutional Commission of Ethics of the Catholic University of Bukavu).

\section{Variables}

The collection of the data was accomplished by means of the files of childbirth established systematically for each woman. Caesarean section was the dependent variable. Independent variables were socio-demographic and anthropometric factors such as age, occupation, marital status, parity, weight, height. Obstetric parameters such as bleeding in the last trimester of pregnancy, foetal weight and presence of previous caesarean section were also sought.

\section{Data processing and analysis}

The data was entered into Microsoft Excel 2013 and exported to Stata. SE, version 13.0 then analysed. Binary logistic regression was done to determine whether the independent variables can predict the outcome variable caesarean section.

The result of the odd ratio was used for interpretation of strength of relationship between independent variables and dependent variable (caesarean section). A p-value less than 0.05 was considered to be statistically significant.

\section{RESULTS}

During the period from January to December 2014, 2170 women delivered at Bukavu Provincial Hospital from whom 491 (22.6\%) gave birth by Caesarean. The results of univariate analysis of the study showed that among the socio-demographic factors, low education level and type of previous delivery were positively associated with caesarean section in this study. 
Table 1: Sociodemographic factors associated with caesarean section.

\begin{tabular}{|c|c|c|c|c|}
\hline & Total & \% of Caesarean & OR (95\% IC) & p-value \\
\hline Age (years) & & & & 0.236 \\
\hline$<20$ & 41 & 4.6 & $1.2(0.61-2.23)$ & \\
\hline $20-35$ & 336 & 53.7 & 1.0 & \\
\hline$>35$ & 89 & 57.3 & $1.4(0.90-2.29)$ & \\
\hline Education level & & & & 0.040 \\
\hline$\leq$ Primary education & 98 & 59.2 & $1.6(1.01-2.51)$ & \\
\hline$\geq$ Secondary education & 368 & 47.5 & 1.0 & \\
\hline Parity & & & & 0.271 \\
\hline Primiparous & 143 & 53.8 & $1.2(0.84-1.85)$ & \\
\hline Pauciparous & 97 & 43.3 & 1.0 & \\
\hline Multiparous & 226 & 50.4 & $1.0(0.71-1.48)$ & \\
\hline Height (cm) & & & & 0.411 \\
\hline$<150$ & 6 & 66.7 & $2.0(0.36-11.12)$ & \\
\hline$\geq 150$ & 460 & 49.8 & 1.0 & \\
\hline Type of previous delivery & & & & 0.000 \\
\hline Caesarean & 91 & 86.8 & $9.4(4.97-17.93)$ & \\
\hline Vaginal delivery & 375 & 41.1 & 1.0 & \\
\hline Have antenatal follow up & & & & 0.565 \\
\hline No & 29 & 44.8 & $0.8(0.37-1.70)$ & \\
\hline Yes & 437 & 50.3 & 1.0 & \\
\hline
\end{tabular}

Table 2: Admission characteristics factors associated with caesarean section.

\begin{tabular}{|llllc|}
\hline Referral status & Total & \% of caesarean & OR $(95 \%$ IC) & p-value \\
\hline Referred emergently & 40 & 85.0 & $6.5(2.65-15.71)$ & \\
\hline Self-admission & 426 & 46.7 & 1.0 & 0.000 \\
\hline Membrane state & & & & \\
\hline Ruptured & 96 & 82.3 & $6.5(3.71-11.44)$ & \\
\hline Intact & 370 & 41.6 & 1.0 & 0.106 \\
\hline Gestational age (weeks) & 64 & 59.4 & $1.5(0.90-2.65)$ & \\
\hline$<38$ & 398 & 40.8 & 1.0 & \\
\hline $38-42$ & 6 & 65.2 & $1.7(0.94-2.31)$ & 0.000 \\
\hline$>40$ & & & & \\
\hline Moment of delivery & 284 & 60.0 & $2.8(1.91-4.14)$ & \\
\hline Day shift $(8: 00 \mathrm{am}-3: 30 \mathrm{pm})$ & 182 & 34.6 & 1.0 & \\
\hline Night shift $(4: 00 \mathrm{pm}-7: 30 \mathrm{am})$ & & &
\end{tabular}

Primiparous and multiparous whose last delivery was by caesarean had significantly higher odds of caesarean than those whose last delivery was vaginal (Table 1).

Concerning characteristics of parturient at the admission, there was a significant association between referral status, membrane state or moment of delivery and caesarean section (Table 2).

The results of univariate analysis of the study showed that among the obstetric and clinical factors, history of arterial hypertension or vaginal bleeding in third trimester were positively associated with delivery by caesarean section. A significant statistical relationship was found between history of foetal distress and caesarean section ( $\mathrm{p}$ $<0.05)$.
There was a strong association between caesarean section and previous caesarean section $(\mathrm{OR}=10.4 ; \mathrm{p}=0.001)$.

Foetal weight (foetal macrosomia) was positively associated with caesarean section $(\mathrm{OR}=1.9 ; \mathrm{p}=0.028)$. Table 3 presents the obstetric and clinical factors.

After binary logistic regression for all factors documented in the study, history of foetal distress $(\mathrm{OR}=6.9 ; \mathrm{p}=0.001)$, history of third trimester vaginal bleeding ( $\mathrm{OR}=6.3 ; \mathrm{p}=0.003)$, type of previous delivery (caesarean section, $\mathrm{OR}=5.8 ; \mathrm{p}=0.000$ ), referral status (referred emergently, $\mathrm{OR}=5.7 ; \mathrm{p}=0.000$ ) and previous caesarean section $(\mathrm{OR}=3.6 ; \mathrm{p}<0.008)$ were important predictors of caesarean section (Table 4). 
Table 3: Clinical and obstetric factors associated with caesarean section.

\begin{tabular}{|lllll|}
\hline History of arterial hypertension & Total & $\%$ of caesarean & OR $(95 \%$ IC) & p-value \\
\hline Yes & 25 & 72.0 & $2.7(1.10-6.60)$ & 0.023 \\
\hline No & 441 & 48.8 & 1.0 & \\
\hline Vaginal bleeding in $\mathbf{3}^{\text {rd }}$ trimester & & & & \\
\hline Yes & 27 & 85.2 & $6.3(2.13-18.43)$ & \\
\hline No & 439 & 47.8 & 1.0 & 0.000 \\
\hline History of foetal distress & & & & \\
\hline Yes & 24 & 83.3 & $5.4(1.80-15.98)$ & 0.066 \\
\hline No & 442 & 48.2 & 1.0 & \\
\hline Previous urinary infections & & & & \\
\hline Yes & 32 & 34.4 & $0.5(0.23-1.06)$ & \\
\hline No & 434 & 51.2 & 1.0 & \\
\hline Previous caesarean section & & & & \\
\hline Yes & 64 & 89.1 & $10.4(4.65-23.48)$ & \\
\hline No & 402 & 43.8 & 1.0 & \\
\hline Birth weight & & & & \\
\hline Low weight & 49 & 59.2 & $1.5(0.82-2.76)$ & \\
\hline Normal weight & 364 & 46.7 & 1.0 & \\
\hline Foetal macrosomia & 53 & 64.2 & $1.9(1.06-3.48)$ & \\
\hline Perineal cicatrix & & & & \\
\hline Yes & 101 & 54.5 & $1.2(0.80-1.95)$ & \\
\hline No & 365 & 48.8 & 1.0 & \\
\hline
\end{tabular}

Table 4: Logistic regression identifying predictive factors of caesarean section.

\begin{tabular}{|lccc|}
\hline $\begin{array}{l}\text { History of fetal } \\
\text { distress }\end{array}$ & 6.9 & $2.15-21.91$ & 0.001 \\
\hline $\begin{array}{l}\text { History of } 3^{\text {rd }} \\
\text { trimester bleeding }\end{array}$ & 6.3 & $1.87-21.03$ & 0.003 \\
\hline $\begin{array}{l}\text { Type of previous } \\
\text { delivery }\end{array}$ & 5.8 & $2.82-11.98$ & 0.000 \\
\hline $\begin{array}{l}\text { Referral status } \\
\begin{array}{l}\text { Previous } \\
\text { caesarean section }\end{array}\end{array}$ & 5.6 & $2.20-14.90$ & 0.000 \\
\hline $\begin{array}{l}\text { Moment of } \\
\text { delivery (day) }\end{array}$ & 2.7 & $1.73-4.21$ & 0.000 \\
\hline
\end{tabular}

\section{DISCUSSION}

This study reveals important information regarding the cesarean section and the factors associated with it. In this study, $22.6 \%$ of mothers delivered by caesarean section. Our caesarean section rate is above the established fork of the World Health Organization. ${ }^{16}$ On another hand, ptresent rate is much lower than the rate of $40.1 \%$ found in study in Lagos-Nigeria and $43 \%$ rate from public hospitals in Brazil. ${ }^{17,18}$

Present high caesarean section rate is due to high rate of emergency sections $(85.0 \%)$, where referral cases are managed from 5 districts and their peripheries as it is the only tertiary care facility in South Kivu Health Division.
But, attention should be paid to avoid unjustified caesarean section which presents not only medical complications but also socio-economic consequences for the family.

In this Provincial hospital, foetal distress, third trimester vaginal bleeding, last delivery by cesarean, referral status, previous caesarean section, and delivery during the day shift (8:30 am to 4:00 pm) were independent predictors of caesarean.

Potential weaknesses of this study include its design, case-control in which some medical cards were insufficiently filled or did not contain all needed parameters. No association was found between mother's age and caesarean section. Thus, a high proportion of caesarean section $(57.3 \%)$ was found among women whose age was above 35 years old. Other studies on the same subject showed that advanced maternal age remain a leading factor associated with caesarean section. ${ }^{16,1920}$ This can be explained by the fact that older women are more likely to experience pregnancy complications such as diabetes, hypertension and pre-eclampsia.

In the present study, the last delivery by caesarean or previous caesarean section was found to be statistically significant as a predictive factor for caesarean section.

Other researchers reported the same observation. ${ }^{21-24}$ It is known that previous caesareans were among the principal medical indications of a cesarean in literature worldwide, 
especially in developing countries. Another probable explanation should be the fact that a woman with previous caesarean is at the risk of a uterus rupture, a vaginal bleeding due to the placenta previa during the pregnancy.

This study showed that the foetal distress was the strong predictive factor of caesarean section. Other studies have also found foetal distress to be a predictive factor for caesarean section. ${ }^{25,26}$ Monitoring of foetal pulse should be done in labour room in order to intervene early.

The referral status for delivery was positively associated with caesarean section in the present study. Parturient referred emergently were more at risk to deliver by caesarean than those whom appear at the hospital without referral. Another study shows that the level of caesarean section among medically referred women is higher since they have been found to have a higher risk of complications. ${ }^{27}$

Caesarean section becomes the one of needed care for them in such case. It is necessary to make a serious monitoring of such category of women.

The moment of delivery (day shift) was also found to be positively associated with delivery by caesarean section. Freitas found that convenience of the team on duty influences type of delivery. ${ }^{22}$ Technically, it is difficult to explain that association. But, it is more logical and easy to deal with those cases during the day than in the night because the team day is bigger and more relaxed than the night team.

History of third trimester vaginal bleeding was found to be significantly associated with caesarean section ( $\mathrm{p}=$ 0.003). Bleeding in third trimester of pregnancy constitutes an emergency in obstetrics. Then, in order to rescue the neonate and to preserve mother health, we have to intervene on time by caesarean. Above findings is in agreement with Akinola's results. ${ }^{17}$

\section{CONCLUSION}

Based on the findings of this study, history of foetal distress, history of bleeding in $3^{\text {rd }}$ trimester, type of previous delivery, referral status, previous caesarean section and moment of delivery were positively associated with increased risk of caesarean section at Bukavu Provincial Hospital.

Preventing the increased caesarean section in the present study area, an improving of prenatal care and reinforcement capacities of health care professionals on practice of compressive obstetric care remain the cornerstone in practice of convincing Caesareans. We strongly recommend that these issues be taken into consideration in order to strengthen the mother and child health programs in South Kivu Health Division.

\section{ACKNOWLEDGMENTS}

The authors would like to thank Bukavu Provincial Hospital for permission given to review patient's data. Authors also thank ISTM staff for their support in collecting data. Finally, authors are grateful to $\mathrm{Mr}$. Narcisse Mubalama who helped in translation of this manuscript draft. To the late Professor Mvula Théodore who supervised this work but could not see the outcome of this work.

Funding: No funding sources Conflict of interest: None declared

Ethical approval: The study was approved by the Institutional Ethics Committee

\section{REFERENCES}

1. Hogan MC, Foreman KJ, Naghavi M, Ahn SY, Wang M, Murray CJ. Maternal mortality for 181 countries, 1980-2008: a systematic analysis of progress towards Millennium Development Goal 5. Lancet. 2010;375:1609-23.

2. WHO, UNFPA and the World Bank. Trends in maternal mortality: 1990 to 2008. Estimates developed by WHO, UNICEF. 2010.

3. Mushira US, Ramanathan M. Delivery-related complications and determinants of caesarean section rates in India. Health Policy Planning. 2002;17(1):90-8.

4. World Health Organization and UNICEF. Indicators to monitor maternal health goals: Report of a technical working group, Geneva, 8-12 November 1993. 1994. Available at http://apps.who.int/iris/handle/10665/60261

Accessed 16 October 2015.

5. Menacker F, Declercq E, Macdorman MF. Cesarean delivery: background, trends, and epidemiology. Seminars in perinatology. 2006;30(5):235-24.

6. Leone T, Padmadaas SS, Mathews Z. Community factors affecting rising caesarean section rates in developing countries: an analysis of six countries. Social Science Med. 2008;67(8):1236-46.

7. Althabe F, Sosa C, Belizan JM, Gibbons L, Jacquerioz F, Bergel E. Caesarean section rates and maternal and neonatal mortality in low, medium, and high-income countries: an ecological study. Birth. 2006;33(4):270-7.

8. Stanton CK, Holtz SA. Levels and trends in cesarean birth in the developing world. Stud Fam Plan. 2006;37(1):41-8.

9. Dumont A, de Bernis L, Bouvier-Colle MH, Breart G, MOMA Study Group: Caesarean section rate for maternal indication in sub-Saharan Africa: a systematic review. Lancet. 2001;358(9290):1328-33.

10. Moore B. Appropriate technology for birth. Lancet. 1985;326(8458):87.

11. Gibbons L, Belizan J, Lauer J, Betran A. Inequities in the use of caesarean sections in the World. Am J Obstet Gynecol. 2012;206:331. 
12. Gholitabar M, Ullman R, James D, Griffiths M: Guideline development group of the national institute for health and clinical excellence: caesarean section: summary of updated NICE guidance. BMJ. 2011;343:d7108.

13. Kongnyuy EJ, Hofman JJ, van den Broek N. Ensuring effective essential obstetric care in resource poor settings. BJOG. 2009;116(1):41-7.

14. Deboutte D, O'Dempsey T, Mann G, Faragher B. Cost-effectiveness of caesarean sections in a postconflict environment: a case study of Bunia, Democratic Republic of the Congo. Disasters. 2013;37(1):S105-20.

15. Chu K, Cortier H, Maldonado F, Mashant T, Ford N, Trelles M. Cesarean Section rates and indications in Sub-Saharan Africa: a multi-country study from Médecins sans Frontieres. PLoS ONE. 2012;7(9):e44484.

16. Busaidi A, Al-Farsi Y, Ganguly S, Gowri V. Obstetric and non-obstetric risk factors for cesarean section in Oman. Oman Med J. 2012;27(6):478-481.

17. Akinola OI, Fabamwo AO, Tayo AO, Rabiu KA, Abisomo OY, Alokha ME. Caesarean section: an appraisal of some predictive factors in Lagos Nigeria. BMC Pregnancy Childbirth. 2014;14(1):217.

18. Mendoza-Sassi RA, Cesar JA, Silva PR, Denardin G, Rodrigues MM. Risk factors for cesarean section by category of health service. Rev Saude Publica. 2010;44(1):80-9.

19. Patel RR, Peters TJ, Murphy DJ and the ALSPAC Study Team. Prenatal risk factors for caesarean section. Analyses of the ALSPAC cohort of 12944 women in England. Int J Epidemiol. 2005;34:353-67.

20. Tebeu PM, Mboudou E, Halle G, Kongnyuy E, Nkwabong E, Fomulu JN. Risk factors of delivery by caesarean section in Cameroon (2003-2004): a regional hospital report. ISRN obstetrics and gynecology. 2011;2011.
21. Geldam AD, Audu BM, Kawuwa BM, Obed JY. Rising trend and indicators of caesarean section at the University of Maiduguri teaching hospital, Nigeria. Ann Afr Med. 2009;8(2):127-32.

22. Freitas PF. The epidemic of caesarean sections in Brazil, factors influencing type of delivery in Florianópolis, South Brazil. Londres: Universidade de Londres; 1999.

23. Bakkali ME, Azzouzi Y, Khadmaoui A, Ahami AO, Boubel $O$. The risk factors associated with the practice of caesarean section in pregnant women at the maternity hospital of IDRISSI Hospital in the Gharb Morocco region. European Sci J. 2014;10(9):226-37.

24. Rageth JC, Juzi C, Grossenbacher H. Delivery after previous cesarean: a risk evaluation. Swiss Working Group of Obstetric and Gynecologic Institutions. Obstet Gynecol. 1999;93:332-7.

25. Talas BB, Altinkaya SO, Talas H, Danisman N, Gungor T. Predictive factors and short-term fetal outcomes of breech presentatiom: a case-control study. Taiwan J Obstet Gynecol. 2008;47 (4):402-7

26. Strong TH, Phelan JP, Alm MO, Sarno AP. Vaginal birth after cesarean delivery in the twin gestation. Am J Obste Gynecol.1989;161(1):29-32.

27. Sorbye IK, Vangen S, Oneko O, Sundby J, Bergsjo P. Caesarean section among referred and selfreferred birthing women: a cohort study from a tertiary hospital, northeastern Tanzania. BMC Pregnancy Childbirth. 2011;1:55.

Cite this article as: Mulongo MP, Mwamini CJ, Mukanire N, Kyambikwa BC, Mvula MT. Factors associated with caesarean section at Bukavu Provincial Hospital in Democratic Republic of Congo. Int J Reprod Contracept Obstet Gynecol 2017;6:5219-24. 